\title{
Predictors of Response to Occipital Nerve Stimulation in Refractory Chronic Headache
}

\author{
${ }^{1}$ Sarah Miller MBBS, ${ }^{2}$ Laurence Watkins FRCS, PhD, ${ }^{1}$ Manjit Matharu FRCP, PhD \\ ${ }^{1}$ Headache Group, Institute of Neurology and The National Hospital for Neurology and \\ Neurosurgery, Queen Square, London, UK \\ ${ }^{2}$ Department of Neurosurgery, Institute of Neurology and The National Hospital for \\ Neurology and Neurosurgery, Queen Square, London, UK
}

Prepared For: CEPHALALGIA

No characters in title: 85

Abstract: 229

Body: 3639

Tables: 3

Supplementary Table 2

References: 36

\section{Corresponding Author:}

Dr Sarah Miller

Clinical Research Fellow

Headache Group, Institute of Neurology and The National Hospital for Neurology and

Neurosurgery, Queen Square, London WC1N 3BG

Email: sarah.miller.12@ucl.ac.uk

Tel: $\quad+447595900535$

Fax: $\quad+447092120797$ 


\section{Running Title:}

ONS Predictors

\section{Key Words:}

Occipital nerve stimulation; Predictors; Migraine; Cluster headache; Hemicrania continua; SUNCT; SUNA

\section{Author contributions:}

SM: data collection, analysis and interpretation of data, drafting and revision of manuscript. LW performed surgery and manuscript revision MSM study concept, recruitment of subjects, interpretation of data and manuscript revision. 


\begin{abstract}
Occipital nerve stimulation (ONS) is a promising treatment for refractory chronic headache disorders but is invasive and costly. Identifying predictors of response would be useful in selecting patients. We present the results of an open-label prospective cohort study of 100 patients (35 chronic migraine, 33 chronic cluster headache, 20 short-lasting unilateral neuralgiform headache attacks and 12 hemicrania continua) undergoing ONS using a multivariate binary regression analysis to identify predictors of response.
\end{abstract}

Response rate of the cohort was $48 \%$. Multivariate analysis showed short lasting unilateral neuralgiform headache attacks (OR 6.71; 95\% CI 1.49-30.05; $\mathrm{p}=0.013$ ) and prior response to greater occipital nerve block (OR 4.22; 95\% CI 1.35-13.21; $\mathrm{p}=0.013$ ) were associated with increased likelihood of response. Presence of occipital pain (OR 0.27; 95\% CI 0.09$0.76 ; \mathrm{p}=0.014$ ) and the presence of severe anxiety and/or depression (as measured on hospital anxiety and depression score) at time of implantation (OR 0.32; 95\% CI $0.11-0.91 ; \mathrm{p}=0.032$ ) were associated with reduced likelihood of response.

Possible clinical predictors of response to ONS for refractory chronic headaches have been identified. Our data shows that those with short-lasting unilateral neuralgiform headache attacks respond better than those with chronic migraine and that a prior response to greater occipital nerve block is associated with positive outcomes. This study suggests that the presence of occipital pain and severe mood disorder at time of implant are both associated with poor outcomes to ONS. 


\section{INTRODUCTION}

Occipital nerve stimulation (ONS) is a promising treatment for medically refractory chronic headache disorders. Open-label studies have demonstrated possible efficacy in chronic migraine $(\mathrm{CM})$, chronic cluster headache $(\mathrm{CCH})$, hemicrania continua $(\mathrm{HC})$ and short lasting unilateral neuralgiform headache attacks (short lasting unilateral neuralgiform headache attacks with conjunctival injection and tearing [SUNCT] and short lasting unilateral neuralgiform headache attacks with autonomic features [SUNA]). ${ }^{1-7}$ However, the results from a small number of controlled trials in CM have been disappointing. The ONSTIM (Occipital Nerve Stimulation for the Treatment of Chronic Migraine Headache) study reported a positive effect of ONS with a $50 \%$ reduction in headache frequency or a three-point reduction in pain score in $39 \%$ of the active group compared to $6 \%$ in a shamstimulation group. ${ }^{8}$ The PRISM (Precision Implantable Stimulator for Migraine) study failed to find a difference in the reduction of migraine days between active and shamstimulation groups in a group including treatment refractory chronic migraine patients. ${ }^{9} \mathrm{~A}$ randomized double-blind study by Silberstein et al. (The St Jude Medical Study) also failed to show a significant difference between active and control groups in the number of patients reporting a 50\% reduction in visual analogue scores but did find a significant difference in those receiving at least a $30 \%$ reduction. ${ }^{10}$

Given these varied results taken together with the invasive nature of the treatment and a relatively high cost, it is crucial that outcome predictors are identified. Although various predictors have been proposed no long-term cohorts have looked at this issue. 


\section{METHODS}

\section{Patients}

One hundred patients with medically refractory chronic headache disorders who had undergone ONS at the National Hospital for Neurology and Neurosurgery, Queen Square, London, UK between February 2007 and June 2014 were identified from a prospectively completed clinical database. All patients were offered ONS under the supervision of our institution's Clinical Effectiveness Supervisory Committee (CESG) with arrangements for clinical governance, consent and audit in place. The procedure was provided as a "humanitarian intervention" and ethics board approval for data collection and publication was granted by Northwick Park Hospital Research Ethics Committee, Hampstead, London, UK.

All patients were seen by and operated upon by a single multidisciplinary specialty headache clinic and were diagnosed according to the International Classification of Headache Disorders 2nd Edition. ${ }^{11}$ All patients had failed to respond to multiple prophylactic medications from several different classes. A failed trial was defined as an unsatisfactory response, development of intolerable side effects or valid contraindication to the use of the drug. All patients with a diagnosis of medication overuse had undergone a period of medication withdrawal to exclude medication overuse headache. ${ }^{11}$ All patients had received a greater occipital nerve (GON) block, either unilateral or bilateral depending on pain laterality. Greater occipital nerve block was conducted using $2 \mathrm{ml} 2 \%$ lidocaine and $80 \mathrm{mg}$ depomedrone injected in the suboccipital area at a point lying on the medial third of a line drawn between the inion and mastoid process ${ }^{12}$. Response to GON block was defined as a patient reporting a $50 \%$ or more improvement in headache frequency or severity lasting at 
least two weeks. Response to GON block was not used, however, as an inclusion criteria for ONS insertion. Intractability is defined by the International Headache Society (IHS) for chronic migraine and chronic cluster headache ${ }^{13}$ but not for short lasting unilateral neuralgiform headache attacks or hemicrania continua, therefore, local criteria were developed (Table 1).

This study only included patients with a single chronic headache type. Patients with multiple headache phenotypes were not considered as the inclusion of multiple outcomes from a single patient may have caused bias in efficacy data. One hundred patients were identified with a single chronic headache disorder.

\section{Surgical Procedure}

Subjects were implanted with devices from Medtronic Inc. (Minneapolis, MN, USA) (91 patients) and St Jude Medical (Plao, TX, USA) (9 patients). ONS systems were implanted as described elsewhere and bilateral ONS electrodes were placed in all patients. ${ }^{7}$ Trial stimulation was not employed as our unit data does not feel that current data supports it as a useful indicator of long-term outcome. Implantable pulse generators (IPG) were placed in the abdomen or subclavicular regions.

Patients were provided with remote controls to allow adjustment of stimulation amplitude and were asked to use continuous tonic stimulation. Polarity of the electrodes was adjusted to achieve comfortable bilateral paresthesia in the occipital region. Medications were changed as needed during follow-up at the discretion of the treating specialist. Further details on the programming values used are available in papers from this group on the 
outcomes of ONS in chronic migraine ${ }^{7}$, chronic cluster headache ${ }^{14}$, short-lasting unilateral neuralgiform headache attacks (accepted but awaiting publication) and hemicrania continua $^{15}$.

\section{Data Collection}

The primary aim for this study was the identification of clinical predictors of response to ONS. The primary outcome measure was clinical response to ONS. Clinical response to ONS has not yet been defined in the literature, however, based on previous publications on ONS for chronic headache $3,5,7-10,16$ and IHS recommendations for outcome measures for $\mathrm{CM}^{17}$ we defined a positive response to ONS as being a $50 \%$ or more reduction in either attack frequency (for $\mathrm{CCH}$ and short lasting unilateral neuralgiform headache attacks) or in moderate-to-severe headache days (for CM and HC). Moderate-to-severe headache days were defined as days with pain scoring a peak intensity of at least four on the verbal rating scale (VRS) lasting at least four hours or of any duration or intensity if painkillers were taken. ${ }^{17}$ Patients were asked to complete a headache diary recording the frequency, severity (on a verbal rating scale $[\mathrm{VRS} ; 0=$ no pain to $10=$ extreme pain]) and duration of headaches for four weeks prior to implant and for two weeks prior to each follow-up visit. Diaries were used to calculate a mean daily attack frequency or monthly moderate-to-severe headache days as appropriate.

Secondary outcome measures included response rates in individual headache phenotypes, and affect scores (Hospital Anxiety [HAD-A] and Depression [HAD-D] scores). 
Data were collected prospectively from February 2007 and entered onto a clinical database (Microsoft Excel, Microsoft Corporation, Redmond, WA, USA). Data collected included demographics, diagnosis, headache frequency, severity and duration, previous and current treatments, and headache characteristics.

\section{Statistics}

All statistical analyses were conducted using IBM SPSS Statistics version 22 (IBM Corp. Int.). A last observation carried forward technique was used in the case of missing data. Descriptive statistics were summarized as appropriate. Data is presented as mean and standard deviation (SD) unless otherwise stated. All statistical tests were two-sided with a significance level of 95\%. Within group differences were examined using paired t-tests, Wilcoxon paired test or McNemar's test as appropriate. Testing for between group differences was performed using two sample t-tests, one-way ANOVA, Chi-square or Fisher's exact test as appropriate.

Binary logistic regression analysis were carried out to predict ONS outcome for the cohort using the following independent variables at time of implant: headache phenotype, presence of occipital pain (defined as any pain reported in the C2-C3 distribution), presence of coexisting non-headache pain conditions (Supplementary Table 1), presence of severe anxiety or depression (defined as a score of $\geq 15$ on HAD-A and/or HAD-D), previous response to greater occipital nerve (GON) block (defined as patient reporting a $50 \%$ or more improvement in their headaches lasting more than 2 weeks), presence of medication overuse (defined as more than 10 days a month of opiates, ergots, triptans or combination-analgesics use or 15 days a month of simple analgesia or non-steroidal anti-inflammatory agents use in 
those with diagnosed $\mathrm{CM}$ or $\mathrm{HC}$ ) and the presence of co-existent episodic headache disorders. All variables were predefined in advance of the data analysis.

\section{RESULTS}

\section{Baseline}

One hundred patients with a single chronic headache diagnosis underwent ONS implantation between February 2007 and June 2014. The mean (SD) age at implant was 48.46 (12.26) years and $55 \%$ of the group was male. The cohort consisted of 35 patients with CM, 33 patients with $\mathrm{CCH}, 20$ with short lasting unilateral neuralgiform headache attacks and twelve with HC. Demographics of the whole group are presented in Table 2.

\section{Final Follow Up}

The mean (SD) time from implant to final follow-up was 45.60 (21.69) months with a range of 13 months to 8 years. (Table 2). At the time of final follow-up, six patients had had their ONS devices permanently removed (five for lack of efficacy and one due to intractable pain over the neck and chest leads). Of those removed for lack of efficacy two were CM patients (removed at two years and at 11 months) and three were $\mathrm{CCH}$ patients (removed at two years at 14 months and at nearly five years). The one removed due to intractable pain over the leads was a $\mathrm{CCH}$ patient (removed at 20 months). 


\section{Response Rate}

A positive response to ONS was defined as a $50 \%$ or more reduction in a patient's mean daily attack frequency or monthly moderate-to-severe headache days. The response rate of the whole cohort was $48 \%$. The response rate of the individual phenotypes was $28.5 \%$ $(\mathrm{n}=10)$ for $\mathrm{CM}, 54.5 \%(\mathrm{n}=18)$ for $\mathrm{CCH}, 75 \%(\mathrm{n}=15)$ for short lasting unilateral neuralgiform headache attacks and $41.7 \%(n=5)$ for $\mathrm{HC}$.

\section{Univariable associations with outcome}

Baseline characteristics assessed for association with response to ONS are shown in Table 3. Variables associated with a positive outcome to ONS were CCH [OR 2.56 (95\% CI 1.05, 6.24)] $(\mathrm{p}=0.021)$ and the presence of short lasting unilateral neuralgiform headache attacks [OR $4.27(95 \%$ CI 1.28, 15.07)] $(\mathrm{p}=0.007)$. Variables associated with a negative outcome to ONS were the presence of CM [OR $0.28(0.10,0.74)](\mathrm{p}=0.004)$ and occipital head pain [OR $0.26(95 \%$ CI 0.10, 0.64)] $(\mathrm{p}=0.001)$.

\section{Multivariable associations with outcome}

Short lasting unilateral neuralgiform headache attacks were associated with increased likelihood of response when compared to CM [OR 6.71 (95\% CI 1.49, 30.05)] ( $\mathrm{p}=0.013)$. A previous positive response to GON block was associated with a positive response to ONS [OR 4.22 (95\% CI 1.35, 13.21)] $(\mathrm{p}=0.014)$. A reduced likelihood of response was associated with the presence of occipital pain [OR $0.27(95 \%$ CI $0.09,0.76)](\mathrm{p}=0.014)$ and severe 
anxiety and/or depression at the time of implant [OR 0.32 (95\%CI 0.11, 0.91)] $(\mathrm{p}=0.032)$ (Table 3).

\section{DISCUSSION}

Identifying predictors of response to ONS is important due to the high cost and invasiveness of the procedure. This is the first study to specifically examine predictors for ONS using multivariate analysis to identify clinical variables associated with response to ONS. Predictors were selected due to their use as inclusion/exclusion criteria in previous studies of ONS or on the basis of previous suggestions of their association with headache and chronic pain outcome..$^{8-10,18-20}$

Univariate analysis showed both $\mathrm{CCH}$ and short lasting unilateral neuralgiform headache attacks are associated with a two and four times increased likelihood of response respectively, whereas $\mathrm{CM}$ was associated with $72 \%$ reduced likelihood of response. Presence of occipital pain was another negative predictor showing a 74\% reduced likelihood of response.

Multivariate analysis suggested that, when compared to $\mathrm{CM}$, short lasting unilateral neuralgiform headache attacks had a nearly seven times increased likelihood of positive response to ONS. The multivariate analysis also suggested that a previous positive response to GON block was associated with a four times higher likelihood of positive outcome. Negative predictors again included the presence of occipital pain (73\% less likely to respond) but also the presence of severe anxiety and/or depression with a $68 \%$ reduction in likelihood of response. 
The negative association between the presence of occipital pain and outcome is of significant interest as it has been an inclusion criterion in controlled studies of ONS. If it is a negative predictor this may explain why the results of studies were less than convincing. The potential reasons for occipital pain predicting poor outcome are unclear. Although one could speculate that those with posterior head pain may be more prone to painful stimulation effects leading them to be intolerant of stimulation this was not borne out in subgroup analysis. Our work suggests that there are other reasons, as yet unaccounted for, as to why occipital pain may influence ONS outcome.

It is acknowledged that depression and anxiety can be associated with worsening pain or an unimproved situation despite treatment. ${ }^{21}$ Mood disorders and catastrophising have been found to be predictive of a poor outcome to lower back pain ${ }^{22}$ and interestingly to spinal cord stimulation for lower back pain. ${ }^{23}$ The reasons for this association are not clear, as the psychosocial model of chronic pain is relatively complex. However, specific to neurostimulation, functional imaging studies report ONS affecting higher pain centers such as the insula and anterior cingulate regions ${ }^{2}$ both of which also have a role in emotional processing and mood. There may, therefore, be a neurochemical basis for the lower response rates due to these centres influencing anti-nociceptive processing in those with mood disorders. Current recommendations stress the importance of psychological input in the assessment and management of neurostimulation candidates and our data suggests that this is vital.

It is not surprising to observe CM associated with a lower likelihood of response (as seen in the univariate analysis) as this appears to be the case in the published trials and open-label data. From our own experience, we have seen that short lasting unilateral neuralgiform 
attack disorders seem to respond well to ONS and this observation seems to be supported in the analysis. Again, our experience suggests that $\mathrm{CCH}$ has a higher response rate than $\mathrm{CM}$. Univariate analysis showed that $\mathrm{CCH}$ was associated with increased likelihood of response but this was not maintained in the multivariate model. However, the confidence interval of the odds ratio for $\mathrm{CCH}$ response suggest that the true population response lies between a $35 \%$ reduced likelihood of response and an eight times increased likelihood. Clinically, the population estimate suggests a trend for chronic cluster responding better than chronic migraine although statistical significance is not reached. The reason for the observation of a lower response rate in $\mathrm{CM}$ is not yet easily explained. Although it is easy to speculate that the response rate to all phenotypes should be similar given ONS works on the same shared pathway (trigeminocervical complex linking to the trigeminovascular system) in all, we know from clinical experience of other pharmaceutical agents that this concept is too simple. As of yet, the exact mechanism of ONS in different phenotypes is unknown and in fact, new insights into the possible pathogenesis and the pain processing pathways involved in each phenotype is constantly evolving. For example, the concept that hypothalamic activation was only seen in TACs and thus had to be the pathway of major importance has recently been called into question by the work of Schulte et al. who described hypothalamic activation in patients with migraine more than with controls suggesting that the hypothalamus has a crucial rule in pain generation in both migraine and TACs. ${ }^{24}$ However, to explain why response rates are so different raises questions regards the relative importance of the different pathways in the different phenotypes, the possible pathways selectively targeted by ONS in each phenotype or indeed the possibility of differences in the pathways modulated in responders and non-responders to ONS. 
The predictive value of GON block in ONS was initially raised by Weiner and Reed in 1999. ${ }^{18}$ The ONSTIM trial used a response to GON block as an inclusion criterion but sub analysis did not find clear evidence to support a link between response to greater occipital nerve block and ONS. ${ }^{8}$ Schwedt et al. examined 13 patients responses to GON block and ONS for a variety of headache conditions and concluded that response to nerve block did not predict ONS outcome. ${ }^{19}$ However, in their cohort, a response to the nerve block was defined as a $50 \%$ or more reduction in headache severity lasting for at least 24 hours, a much less stringent response than defined in our analysis, which required a response lasting at least 2 weeks. A recent systematic review of open-label data on this issue found no predictive validity of GON block in the outcome of ONS in CM trials but could only find data on 45 patients out of the 133 included in studies. ${ }^{25}$ In that review, the authors state that response to ONS was seen in those reporting no GON block benefit and also, vice versa, that some patients with a previous response to GON block failed to improve with ONS. The authors suggest there is a need for a prospective study on the predictive value of GON block. The reason for conflicting data in our cohort may include the use of a multivariate model, single and stricter definitions of headache response and GON block response rate.

Other potential factors suggested as predictive of ONS outcome have included previous response to transcutaneous (TENS) ${ }^{26}$ or percutaneous nerve stimulation (PENS) ${ }^{27}$ of the occipital region and perceived sensation over the occipital region during ONS treatment ${ }^{28}$, 29 . Although the open-label study by Nguyen et al. suggested that a "good to very good" response to TENS prior to ONS was associated with a significantly higher reduction in pain scores after three years, their data is somewhat flawed. The outcome to TENS was judged by patient's subjective estimate only and given that only those with a good to very good subjective response to TENS were implanted with ONS there is no real negative comparator. 
Kinfe and colleagues used a more robust protocol to examine a group of 12 patients with chronic refractory headache treated with PENS prior to ONS implant (with all patients receiving both treatments). This group concluded that pre-surgical PENS did not identify ONS responders. It is commonly accepted that in order to achieve response to ONS, stimulation programs should be employed that provide a perceptible level of paresthesia over the occiput. Although no large-scale studies have been employed to discover which program parameters provide optimum results there have been small series reporting on both the spread of paresthesia and the use of subthreshold (i.e. non-perceivable) stimulation. Slotty et al compared a group of CM patients and their reported response to ONS as they cycled through treatments with "effective stimulation", "subthreshold stimulation" and no stimulation. ${ }^{28}$ Although they concluded that paresthesia is not an absolute requirement of response, they did find that suprathreshold stimulation was associated with better outcomes. In another series looking at the paresthesia induced during ONS, Trentman et al undertook sensory mapping of patients undergoing ONS. ${ }^{29}$ Although they report that the majority of patients felt paresthesia in the occipital region they also recorded stimulation at more distant sites, albeit rarely. However, the group did not correlate location of paresthesia with outcome although this would be an interesting extension that would help to guide programming technique.

Preventative treatments, including ONS, have been postulated to be less effective in the presence of medication overuse. ${ }^{30}$ However, randomized trials of topiramate and onabotulinumtoxinA have shown these to be efficacious in CM even in those overusing acute medication. ${ }^{31,32}$ An important point to consider is the subtle but important difference between the overuse of acute medication and medication overuse headache. All our patients were screened for medication overuse headache and only implanted if they failed to improve 
following medication detoxification. Our results support the call for further discussions around the classification of $\mathrm{CM}$ with "medication overuse" versus "medication overuse headache" and their impact on treatment outcomes.

Half of our group experienced a positive response to ONS at a mean follow-up time of 45.49 months. A major issue in comparing our data with that from other centers is the huge variability in outcome measures used in the literature. Although for $\mathrm{CCH}$ most centers quote reduction in daily attack frequency, some have also used reduction in pain scores or patient estimates of overall improvement. For CM there is a far greater variety of published outcomes including changes in pain scores, headache days, migraine days, moderate-tosevere headache days, duration of headache and MIDAS. ${ }^{33}$ Our primary outcome measures were based on recommendations from the International Headache Society.

Given the prospective nature of the study, the main weakness is the lack of a placebo control. However, in line with previous publications and against a pure placebo response, our group showed a delay to maximum reported improvement in the order of months and worsening of pain when the device was switched off for any period. More importantly, the placebo rate of ONS in the controlled trials on CM are quoted at 6\%, 17\% and $20 \%$ - all below the outcome seen in our cohort. ${ }^{8-10}$ Chronic daily headache does remit to less than 15 days a month in a proportion of subjects followed in longitudinal studies with a one to four year remission rate of $33-65 \% .{ }^{34-36}$ However, returning to low frequency episodic headache (less than one a week) is less common (14\%). ${ }^{35}$ These studies were conducted in the community and it is likely subjects were different from sufferers in specialist headache clinics. The patient populations seen in the ONS specialist clinics are also progressively negatively selected by treatment response so as to represent those truly chronic and unremitting cases 
from the initial persistent chronic daily headache sufferers in the general population. Therefore, we argue that natural history alone would not explain the improvement seen following ONS in this cohort.

In conclusion, ONS appears to be an effective treatment in highly intractable chronic headache patients. Short lasting unilateral neuralgiform disorder was associated with a better outcome than chronic migraine and a positive response to GON block was also associated with an increased likelihood of response to ONS. The presence of severe anxiety and/or depression and the presence of occipital pain were both found to be associated with a reduced likelihood of response. Predictors of outcome in ONS are crucial in identifying those patients most likely to benefit from costly and invasive procedures. More work is needed to validate these predictors and identify other factors, both clinical and stimulation related, that might be useful in predicting response to ONS.

\section{Acknowledgements:}

We would like to thank Dr Zoe Fox, formerly of The Biomedical Research Centre UCL Institute of Neurology, for her advice on statistical analysis. We would like to thank our Headache Specialist Nurses, especially Mrs Susie Lagrata, for their help with completion of the clinical database and management of the patients. We also thank the patients and their families for their help with this project.

\section{Conflicts of Interest:}

SM has received educational and travel grants from St Jude Medical and Medtronic.

LW serves on the advisory board for St Jude Medical and Medtronic 
MSM serves on the advisory board for Allergan, St Jude Medical and Medtronic and has received payment for the development of educational presentations from Allergan, Medtronic, St Jude Medical and electroCore. 


\section{REFERENCES}

1. Schwedt TJ, Dodick DW, Hentz J, Trentman TL and Zimmerman RS. Occipital nerve stimulation for chronic headache--long-term safety and efficacy. Cephalalgia. 2007; 27: 1537.

2. Matharu MS, Bartsch T, Ward N, Frackowiak RS, Weiner R and Goadsby PJ. Central neuromodulation in chronic migraine patients with suboccipital stimulators: a PET study. Brain. 2004; 127: 220-30.

3. Mueller O, Diener HC, Dammann P, et al. Occipital nerve stimulation for intractable chronic cluster headache or migraine: A critical analysis of direct treatment costs and complications. Cephalalgia. 2013; 33: 1283-91.

4. Burns B, Watkins L and Goadsby PJ. Treatment of intractable chronic cluster headache by occipital nerve stimulation in 14 patients. Neurology. 2009; 72: 341-5.

5. Magis D, Gerardy PY, Remacle JM and Schoenen J. Sustained effectiveness of occipital nerve stimulation in drug-resistant chronic cluster headache. Headache. 2011; 51: 1191-201.

6. Lambru G, Shanahan P, Watkins L and Matharu MS. Occipital Nerve Stimulation in the Treatment of Medically Intractable SUNCT and SUNA. Pain physician. 2014; 17: 29-41.

7. Miller S, Watkins L and Matharu M. Long-term outcomes of occipital nerve stimulation for chronic migraine: a cohort of 53 patients. J Headache Pain. 2016; 17: 68.

8. Saper JR, Dodick DW, Silberstein SD, McCarville S, Sun M and Goadsby PJ. Occipital nerve stimulation for the treatment of intractable chronic migraine headache: ONSTIM feasibility study. Cephalalgia. 2011; 31: 271-85.

9. Lipton R, Goadsby PJ, Cady R, et al. PRISM study: Occipital nerve stimulation for treatment-refractory migraine. Cephalalgia. 2009; 29: 30.

10. Silberstein SD, Dodick DW, Saper J, et al. Safety and efficacy of peripheral nerve stimulation of the occipital nerves for the management of chronic migraine: results from a randomized, multicenter, double-blinded, controlled study. Cephalalgia. 2012; 32: 1165-79.

11. Headache Classification Subcommittee of the International Headache Society. The International Classification of Headache Disorders, 2nd edn. Cephalalgia. 2004; 24: 1-160.

12. Lambru G, Abu Bakar N, Stahlhut L, et al. Greater occipital nerve blocks in chronic cluster headache: a prospective open-label study. Eur J Neurol. 2014; 21: 338-43.

13. Goadsby PJ, Schoenen J, Ferrari MD, Silberstein SD and Dodick D. Towards a definition of intractable headache for use in clinical practice and trials. Cephalalgia. 2006; 26 : 1168-70.

14. Miller S, Watkins L and Matharu M. Treatment of intractable chronic cluster headache by occipital nerve stimulation: a cohort of 51 patients. Eur J Neurol. 2017; 24: 381-90.

15. Miller S, Watkins L and Matharu MS. Treatment of intractable hemicrania continua by occipital nerve stimulation. J Neurol Neurosurg Psychiatry. 2017.

16. Magis D and Schoenen J. Advances and challenges in neurostimulation for headaches. Lancet Neurol. 2012; 11: 708-19.

17. Silberstein S, Tfelt-Hansen P, Dodick DW, et al. Guidelines for controlled trials of prophylactic treatment of chronic migraine in adults. Cephalalgia. 2008; 28: 484-95.

18. Weiner RL and Reed KL. Peripheral neurostimulation for control of intractable occipital neuralgia. Neuromodulation. 1999; 2: 217-21.

19. Schwedt TJ, Dodick DW, Trentman TL and Zimmerman RS. Response to occipital nerve block is not useful in predicting efficacy of occipital nerve stimulation. Cephalalgia. 2007; 27: 271-4. 
20. Tunks ER, Crook $\mathbf{J}$ and Weir R. Epidemiology of chronic pain with psychological comorbidity: prevalence, risk, course, and prognosis. Can J Psychiatry. 2008; 53: 224-34.

21. Guidetti V, Galli F, Fabrizi P, et al. Headache and psychiatric comorbidity: clinical aspects and outcome in an 8-year follow-up study. Cephalalgia. 1998; 18: 455-62.

22. Pinheiro MB, Ferreira ML, Refshauge K, et al. Symptoms of depression as a prognostic factor for low back pain: a systematic review. Spine J. 2016; 16: 105-16.

23. Sparkes E, Duarte RV, Mann S, Lawrence TR and Raphael JH. Analysis of psychological characteristics impacting spinal cord stimulation treatment outcomes: a prospective assessment. Pain physician. 2015; 18: E369-77.

24. Schulte LH, Allers A and May A. Hypothalamus as a mediator of chronic migraine: Evidence from high-resolution fMRI. Neurology. 2017; 88: 2011-6.

25. Kinfe TM, Schuss $P$ and Vatter H. Occipital nerve block prior to occipital nerve stimulation for refractory chronic migraine and chronic cluster headache: Myth or prediction? Cephalalgia. 2015; 35: 359-62.

26. Nguyen JP, Nizard J, Kuhn E, et al. A good preoperative response to transcutaneous electrical nerve stimulation predicts a better therapeutic effect of implanted occipital nerve stimulation in pharmacologically intractable headaches. Neurophysiol Clin. 2016; 46: 69-75.

27. Kinfe TM, Pintea B, Roeske S, Guresir A, Guresir E and Vatter H. Percutaneous nerve field stimulation (PENS) of the occipital region as a possible predictor for occipital nerve stimulation (ONS) responsiveness in refractory headache disorders? A feasibility study. Cephalalgia. 2016; 36: 779-89.

28. Slotty P, Bara G, Kowatz L, et al. Occipital nerve stimulation for chronic migraine: A randomized trial on subthreshold stimulation. Cephalalgia: an international journal of headache. 2015; 35: 73-8.

29. Trentman TL, Zimmerman RS, Seth N, Hentz JG and Dodick DW. Stimulation Ranges, Usage Ranges, and Paresthesia Mapping During Occipital Nerve Stimulation. Neuromodulation: Technology at the Neural Interface. 2008; 11: 56-61.

30. Zeeberg P, Olesen J and Jensen R. Discontinuation of medication overuse in headache patients: recovery of therapeutic responsiveness. Cephalalgia. 2006; 26: 1192-8.

31. Diener HC, Bussone G, Van Oene JC, Lahaye M, Schwalen S and Goadsby PJ. Topiramate reduces headache days in chronic migraine: a randomized, double-blind, placebocontrolled study. Cephalalgia. 2007; 27: 814-23.

32. Silberstein SD, Blumenfeld AM, Cady RK, et al. OnabotulinumtoxinA for treatment of chronic migraine: PREEMPT 24-week pooled subgroup analysis of patients who had acute headache medication overuse at baseline. J Neurol Sci. 2013; 331: 48-56.

33. Chen YF, Bramley G, Unwin G, et al. Occipital nerve stimulation for chronic migraine-a systematic review and meta-analysis. PLoS One. 2015; 10: e0116786.

34. Wang SJ, Fuh JL, Lu SR and Juang KD. Outcomes and predictors of chronic daily headache in adolescents: a 2-year longitudinal study. Neurology. 2007; 68: 591-6.

35. Scher AI, Stewart WF, Ricci JA and Lipton RB. Factors associated with the onset and remission of chronic daily headache in a population-based study. Pain. 2003; 106: 81-9.

36. Lu SR, Fuh JL, Chen WT, Juang KD and Wang SJ. Chronic daily headache in Taipei, Taiwan: prevalence, follow-up and outcome predictors. Cephalalgia. 2001; 21: 980-6. 
21 Miller 


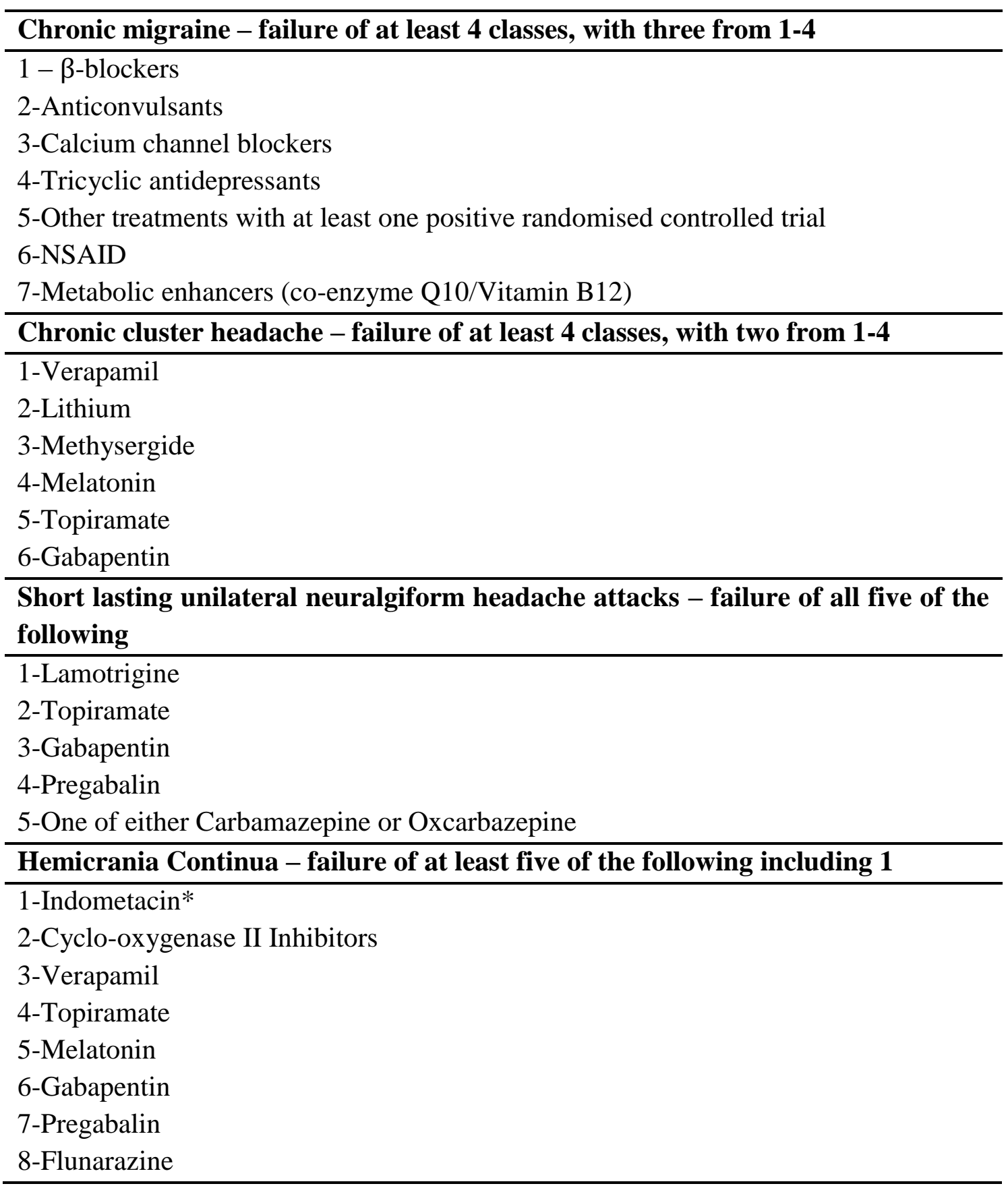

\section{Table 1: Intractable Headache}

Local guidelines used for the diagnosis of medically intractable chronic headache (Chronic migraine and Chronic cluster headache guidelines as per Goadsby et al. ${ }^{11}$; Short lasting unilateral neuralgiform headache attacks as per Lambru et al. ${ }^{6}$ )

*Failure of response to indometacin defined as positive response of headache attacks (thereby confirming diagnosis of hemicrania continua) to indometacin but intolerable side effects 


\begin{tabular}{|c|c|c|c|c|}
\hline & $\begin{array}{l}\text { Whole Group } \\
\qquad(\mathrm{n}=100)\end{array}$ & $\begin{array}{l}\text { Responders } \\
\quad(n=48)\end{array}$ & $\begin{array}{l}\text { Non-Responders } \\
\qquad(\mathrm{n}=52)\end{array}$ & p-value \\
\hline $\begin{array}{r}\text { Mean }( \pm \mathrm{SD}) \\
\text { Range }\end{array}$ & $\begin{array}{c}48.46( \pm 12.26) \\
20-74\end{array}$ & $\begin{array}{c}48.77( \pm 12.73) \\
20-74\end{array}$ & $\begin{array}{c}48.17( \pm 11.93) \\
26-74\end{array}$ & 0.809 \\
\hline $\begin{array}{r}\text { Male: n (\%) } \\
\text { Female: n }(\%)\end{array}$ & $\begin{array}{l}55(55 \%) \\
45(45 \%)\end{array}$ & $\begin{array}{l}26(54.2 \%) \\
22(45.8 \%)\end{array}$ & $\begin{array}{l}29(55.8 \%) \\
23(44.2 \%)\end{array}$ & 0.872 \\
\hline Co-existent pain condition* & $31(31 \%)$ & $17(35.4 \%)$ & $14(26.9 \%)$ & 0.359 \\
\hline $\begin{array}{r}\mathrm{CM} \\
\mathrm{CCH} \\
\text { SUNCT/SUNA } \\
\mathrm{HC}\end{array}$ & $\begin{array}{l}35(35 \%) \\
33(33 \%) \\
20(20 \%) \\
12(12 \%)\end{array}$ & $\begin{array}{l}10(20.8 \%) \\
18(37.5 \%) \\
15(31.3 \%) \\
5(10.4 \%)\end{array}$ & $\begin{array}{l}25(48.1 \%) \\
15(28.8 \%) \\
5(9.6 \%) \\
7(13.5 \%)\end{array}$ & $0.008 * *$ \\
\hline $\begin{array}{r}\text { Co-existent episodic headaches: } \mathbf{n}(\%) \\
\text { Yes: } \mathbf{n}(\%) \\
\text { EM } \\
\text { ECH } \\
\text { Idiopathic Stabbing Headache }\end{array}$ & $\begin{array}{c}23(23 \%) \\
16(16 \%) \\
3(3 \%) \\
4(4 \%)\end{array}$ & $\begin{array}{c}14(29.1 \%) \\
9(18.7 \%) \\
2(4.2 \%) \\
3(6.2 \%)\end{array}$ & $\begin{array}{c}9(17.3 \%) \\
7(13.5 \%) \\
1(1.9 \%) \\
1(1.9 \%)\end{array}$ & 0.159 \\
\hline $\begin{array}{l}\text { Duration of chronic headache (years) } \\
\qquad \begin{array}{r}\text { Mean }( \pm \mathrm{SD}) \\
\text { Range }\end{array}\end{array}$ & $\begin{array}{c}10.18( \pm 8.98) \\
2-48\end{array}$ & $\begin{array}{c}9.81( \pm 8.62) \\
2-46\end{array}$ & $\begin{array}{c}10.52( \pm 9.37) \\
2-48\end{array}$ & 0.696 \\
\hline Pain free days & $11(11 \%)$ & $6(12.5 \%)$ & $5(9.6 \%)$ & 0.645 \\
\hline
\end{tabular}




\begin{tabular}{|c|c|c|c|c|}
\hline $\begin{array}{r}\text { Number of preventatives tried prior to ONS } \\
\text { Mean }( \pm \mathrm{SD}) \\
\text { Range }\end{array}$ & $\begin{array}{c}9.92( \pm 3.38) \\
4-21\end{array}$ & $\begin{array}{c}10.04( \pm 3.69) \\
5-20\end{array}$ & $\begin{array}{c}9.81( \pm 3.10) \\
4-21\end{array}$ & 0.732 \\
\hline Previous response to GON block*** & $26(26 \%)$ & $16(33.3 \%)$ & $10(19.2 \%)$ & 0.108 \\
\hline $\begin{array}{l}\text { Severe anxiety or depression }(\geq 15 \text { on the HAD-A or } \\
\text { HAD-D scale) } \\
\qquad \text { Yes: } n(\%)\end{array}$ & $35(35 \%)$ & $13(27.1 \%)$ & $22(42.3 \%)$ & 0.111 \\
\hline $\begin{array}{l}\text { Medication overuse } \\
\text { (As per ICHD-3beta criteria) }\end{array}$ & $19(19 \%)$ & $11(22.9 \%)$ & $8(15.4 \%)$ & 0.337 \\
\hline Follow-up since implant (months) & $\begin{array}{c}45.60( \pm 21.69) \\
15-97\end{array}$ & $\begin{array}{c}46.16( \pm 21.50) \\
2-92\end{array}$ & $\begin{array}{c}44.86( \pm 22.44) \\
13-97\end{array}$ & 0.768 \\
\hline
\end{tabular}

\section{$\mathrm{SD}$, Standard deviation}

$\mathrm{CCH}$, Chronic cluster headache; CM, Chronic migraine; ECH, Episodic cluster headache; EM, Episodic migraine; GON, greater occipital nerve; HAD-A, Hospital Anxiety and Depression Score - Anxiety component; HAD-D, Hospital Anxiety and Depression Score - Depression component; HC, Hemicrania Continua; ICHD-3beta, International Classification of Headache Disorders 3 beta edition; ONS, Occipital nerve stimulator; SUNA, Short lasting unilateral neuralgiform headache attacks with autonomic features; SUNCT, Short lasting unilateral neuralgiform headache attacks with conjunctival injection and tearing; *Co-existent pain conditions: As detailed in Supplementary table 1; **P value $<0.05$; *** Response to GON block defined as patient reporting a 50\% or more improvement in headache frequency or severity lasting at least 2 weeks

\section{TABLE 2: Patient Demographics and Baseline Clinical and Headache Characteristics.}




\begin{tabular}{|c|c|c|c|c|c|}
\hline \multicolumn{2}{|l|}{ Variable } & \multirow{2}{*}{$\begin{array}{c}\begin{array}{c}\text { Univariable Analysis } \\
\text { Odds Ratio }(\mathbf{9 5 \%} \mathbf{C I})\end{array} \\
0.28(0.10,0.74) \\
2.56(1.05,6.24) \\
4.27(1.28,15.07) \\
0.74(0.18,2.90)\end{array}$} & \multirow{2}{*}{$\begin{array}{c}\text { p-value } \\
0.004^{*} \\
0.021^{*} \\
0.007^{*} \\
0.640\end{array}$} & \multirow{2}{*}{$\begin{array}{c}\text { Multivariable Analysis } \\
\text { Odds Ratio (95\% CI) } \\
\text { Comparator } \\
2.32(0.64,8.43) \\
6.71(1.49,30.05) \\
1.38(0.29,6.52)\end{array}$} & \multirow{2}{*}{$\begin{array}{c}\text { p-value } \\
0.199 \\
0.013^{*} \\
0.679\end{array}$} \\
\hline $\begin{array}{l}\text { Headache } \\
\text { phenotypes }\end{array}$ & $\begin{array}{c}\text { Chronic Migraine } \\
\text { Chronic Cluster Headache } \\
\text { Chronic SUNCT/SUNA } \\
\text { HC }\end{array}$ & & & & \\
\hline $\begin{array}{l}\text { Presence of } \\
\text { medication overuse }\end{array}$ & Yes & $1.63(0.53,5.04)$ & 0.337 & $1.45(0.34,6.07)$ & 0.606 \\
\hline $\begin{array}{l}\text { Presence of non- } \\
\text { headache chronic } \\
\text { pain condition }\end{array}$ & Yes & $1.48(0.58,3.80)$ & 0.359 & $1.65(0.58,4.65)$ & 0.342 \\
\hline $\begin{array}{l}\text { Severe Anxiety or } \\
\text { Depression (HAD- } \\
\text { A/HAD-D } \geq 15)\end{array}$ & Yes & $0.50(0.20,1.2)$ & 0.111 & $0.32(0.11,0.91)$ & $0.032 *$ \\
\hline $\begin{array}{l}\text { Prior response to } \\
\text { GON Block }\end{array}$ & Yes & $2.10(0.77,5.79)$ & 0.108 & $4.22(1.35,13.21)$ & $0.013^{*}$ \\
\hline Occipital Pain & Yes & $0.26(0.10,0.64)$ & $0.001 *$ & $0.27(0.09,0.76)$ & $0.014 *$ \\
\hline $\begin{array}{l}\text { Co-existing episodic } \\
\text { headache disorder }\end{array}$ & Yes & $1.96(0.69,5.66)$ & 0.159 & $1.36(0.39,4.76)$ & 0.626 \\
\hline
\end{tabular}

GON, greater occipital nerve; HC, Hemicrania Continua; SUNA, Short lasting unilateral neuralgiform headache attacks with autonomic features; SUNCT, Short lasting unilateral neuralgiform headache attacks with conjunctival injection and tearing;

Table 3: Results of univariate and multivariate analysis 


\begin{tabular}{|c|c|}
\hline \multicolumn{1}{|c|}{ Pain Syndrome } & $\begin{array}{c}\text { Number } \\
\text { Reporting }\end{array}$ \\
\hline Musculoskeletal Conditions: & $\mathbf{1 6}$ \\
Back Pain & 10 \\
Cervical Spondylosis & 2 \\
Osteoarthritis & 3 \\
EDS-Hypermobility Type & 1 \\
\hline Fibromyalgia (with/without Chronic Fatigue) & $\mathbf{7}$ \\
\hline Gastrointestinal Conditions: & $\mathbf{1 2}$ \\
Irritable Bowel Syndromes & 10 \\
Diverticulitis & 2 \\
\hline Gynaecological Conditions: & $\mathbf{2}$ \\
Endometriosis & 2 \\
\hline Neurological Conditions: & $\mathbf{9}$ \\
Sciatica & 2 \\
Neuropathy & 7 \\
\hline
\end{tabular}

EDS, Ehlers-Danlos Syndrome

Supplementary Table 1: The non-headache related pain conditions reported by the patient cohort. 